\section{$\underset{\substack{\text { hommes } \\ \text { \& migrations }}}{ }$}

\section{Hommes \& migrations}

Revue française de référence sur les dynamiques

migratoires

$1311 \mid 2015$

Femmes et migrations

\title{
La rentrée littéraire de la Porte Dorée
}

\section{Élisabeth Lesne}

\section{(2) OpenEdition \\ Journals}

\section{Édition électronique}

URL : https://journals.openedition.org/hommesmigrations/3402

DOI : 10.4000/hommesmigrations.3402

ISSN : 2262-3353

\section{Éditeur}

Musée national de l'histoire de l'immigration

\section{Édition imprimée}

Date de publication : 1 juillet 2015

Pagination : 192-194

ISBN : 978-2-919040-32-2

ISSN : $1142-852 X$

\section{Référence électronique}

Élisabeth Lesne, «La rentrée littéraire de la Porte Dorée », Hommes \& migrations [En ligne], 1311 | 2015, mis en ligne le 09 février 2016, consulté le 28 juin 2022. URL : http://journals.openedition.org/ hommesmigrations/3402; DOI : https://doi.org/10.4000/hommesmigrations.3402 


\title{
PRIX LITTÉRAIRE
}

\section{LA RENTRÉE LITTÉRAIRE DU PALAIS DE LA PORTE DORÉE}

par ELISABETH LESNE

\begin{abstract}
Lire les livres de la rentrée littéraire sur l'exil alors que dans la presse, les flashs info et les débats à la télé, à la radio, à n'importe quelle heure, partout, partout, il n'est question que du drame des réfugiés, c'est rester au cœur de cette actualité brûlante. Dans ce contexte, que peut apporter la littérature ? Les romans racontent des destins individuels, envisagent I'immigration à hauteur d'hommes et de femmes. Et ça change tout.
\end{abstract}

\section{/// TROIS ROMANS EN PRISE DIRECTE AVEC L'ACTUALITÉ}

\section{Encore de Hakan Günday \\ (Galaade)}

C'est de Turquie, ce "vieux pont entre l'Orient aux pieds nus et l'Occident bien chaussé, sur lequel passe tout ce qui est illégal", que nous vient le roman le plus fort de cette rentrée, le plus dur aussi. Paru en turc en 2013, et excellemment traduit aujourd'hui par Jean Descat, il projette le lecteur dans la tête et les tripes d'un jeune passeur qui cherche à évacuer son passé en le racontant. Dès l'âge de 9 ans, Gazâ est devenu l'assistant de son père, qui convoie en camion jusqu'à la mer Egée la "marchandise qui arrivait trois fois par mois après avoir franchi la frontière d'Iran - il en venait parfois aussi d'Irak et de Syrie". Lui règne sur le réservoir où sont stockés les clandestins dans l'attente du départ. Un "puits infernal" où il va exercer sa toute-puissance et observer "la force du pouvoir": "J'étais le seul à avoir sous mes pieds un laboratoire plein d'êtres humains." Un récit au souffle puissant, où la seule lumière vient d'une petite grenouille en papier qui lui a été offerte par un Afghan, la voix de sa conscience.

\section{Les Échoués de Pascal Manoukian (Don Quichotte)}

Nous sommes au début des années 1990. Lampedusa, Ceuta et Melilla ne sont pas encore si tragiquement célèbres. L'Europe a déjà aboli ses frontières intérieures. Pourtant, Virgil le Moldave, Chanchal le Bangladais, Assan le Somalien et sa fille ont eu affaire aux mêmes trafiquants et aux mêmes exploiteurs que les réfugiés d'aujourd'hui. Le premier est chrétien, le deuxième hindou et le troisième musulman, peu importe, leurs routes se croisent à Villeneuve-le-Roi, en banlieue parisienne, et ils vont s'aider. Ancien reporter de guerre, l'auteur révèle de façon poignante les raisons de leur départ, les humiliations et l'exploitation qui les attendent, en che- 

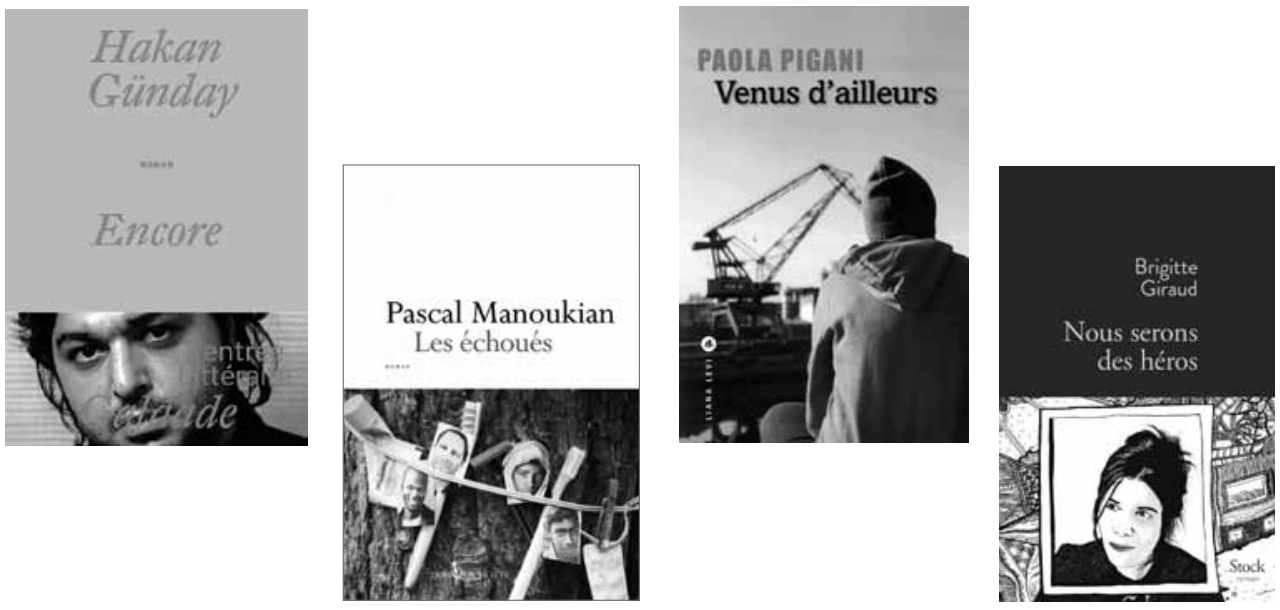

min et une fois arrivés au but, endettés pour des années. La frontière est bien ténue entre migrants économiques et politiques, puisque "la misère et la faim sont une manne intarissable pour les mafieux, les djihadistes, les rebelles et les trafiquants en tout genre", écrit Manoukian. La générosité d'une famille française ne suffira pas à transfigurer leur épopée.

\section{Venus d'ailleurs de Paola Pigani \\ (Liana Levi)}

Paola Pigani suit un frère et une sœur qui ont fui la guerre civile au Kosovo, affrontant les mêmes traumatismes, les mêmes difficultés que les migrants d'aujourd'hui. Débarqués en France en 2000 au Chambon-sur-Lignon, ils vont attendre leur statut de réfugié au milieu de gens venus du monde entier. Cada, Ofpra, récépissé, formulaires à remplir..., comment se repérer, même avec l'aide d'associations humanitaires, quand on ne parle pas français ? Installés enfin dans une grande ville, à Lyon, Simona veut "s'intégrer", elle court à l'Alliance française après ses heures dans un magasin discount. Son frère Mirko, lui, travaille sur un chantier, mais, assailli par les images d'une guerre que les Français paraissent avoir déjà oubliée, il ne s'apaise qu'en laissant des graffs rageurs aux lisières de la ville. Sans pathos, Paola Pigani sait parler des souffrances du déracinement et de la diversité des chemins, même pour ceux qui partagent la même histoire.

\section{/// S'INSTALLER EN FRANCE}

\section{Nous serons tous des héros}

\section{de Brigitte Giraud (Stock)}

À la fin des années 1960, après la mort de son père, militant tué par la dictature de Salazar, Olivio, 8 ans, arrive clandestinement avec sa mère dans la région lyonnaise. En France, ils rejoignent Luis et Linda, qui, même en exil, se sentent encore épiés par la Pide, la police politique de l'État portugais. 


\section{PRIX LITTÉRAIRE}

Le fils et la mère vont trouver du réconfort auprès de deux autres orphelins de leur terre natale. Pour Olivio, c'est son copain Ahmed, un immigré algérien qui l'entraîne dans de drôles de jeux : "le sourire kabyle" et "la corvée de bois", sombres souvenirs de la guerre d'Algérie. Sa mère, elle, va tomber amoureuse de Max, un pied-noir amer d'être devenu un "rapatrié", trahi à la fois "par les Arabes et par la France". Instinctivement, Olivio le tiendra éloigné d'Ahmed. En avril 1974, la révolution des đillets va redonner de la fierté aux Portugais exilés, mais les "enfants d'Algérie" continueront de nourrir leurs ressentiments. Brigitte Giraud analyse finement comment le pays quitté continue de hanter, et de façonner, les exilés.

\section{Sœurs de miséricorde}

\section{de Colombe Schneck}

\section{(Stock)}

En 2005, Azul dispose d'un logement social à Ris-Orangis, ses enfants sont enfin venus la rejoindre, et elle fait des ménages dans les beaux quartiers de Paris. Le chemin et les sacrifices ont été rudes pour arriver à cette "réussite". Azul vient de Bolivie, pays où les femmes émigrent pour nourrir leur famille, tandis que les hommes disparaissent ou flambent au jeu l'argent durement gagné par leurs épouses. Azul a d'abord dû quitter sa mère et son village pour aller au collège à Santa Cruz - Colombe Schneck prend plaisir à décrire la luxuriance de la végétation, les couleurs des étoffes, les vêtements traditionnels des Quechuas. Ensuite, ses enfants et son mari, dans l'espoir de revenir bien vite au pays avec quelques milliers de dollars : un rêve de retour qui s'éloigne, tandis que les enfants commencent leurs études en France. Le décalage est

énorme entre cette immigrée besogneuse, généreuse, battante, et les bourgeoises désœuvrées et vaguement déprimées $d u X V l^{e}$ arrondissement. Mais la bonté est parfois contagieuse et peut donner du sens à la vie.

\section{/// IDENTITÉS VAGABONDES}

\section{La Ballade du calame}

d'Atiq Rahimi (L'Iconoclaste)

Arrivé en France en 1985, à une époque où les Afghans étaient accueillis à bras ouverts, Atiq Rahimi publie aujourd'hui une méditation poétique sur ses origines. Une entreprise vécue sous 
l'emprise d'une angoisse qui fait écho à son "expérience originelle de l'exil": "Une fois à la frontière, le passeur me dit de jeter un dernier regard sur ma terre natale. Je m'arrêtai et regardai en arrière: tout ce que je vis n'était qu'une étendue de neige avec les empreintes de mes pas. Et de l'autre côté de la frontière, un désert semblable à une feuille de papier vierge. Sans aucune trace. Je me suis dit que l'exil serait ça, une page blanche qu'il faudrait remplir." Et d'ajouter : "Me voici trente ans après, las, toujours devant cette page blanche." Comme vidé de mots, grâce aux traits esquissés de la pointe de son calame, il parvient à retrouver les souvenirs de son enfance. Cela donne un livre à la fois dense et aéré, enluminé de "callimorphies", dans un va-et-vient constant entre l'être et les lettres. Citant aussi bien Rûmi et Tagore que Tabucchi, Nietzsche, Hugo et Baudelaire, Atiq Rahimi nous embarque dans son monde, un "métissage de différentes cultures, de différentes religions, de différentes langues...". Un livre à lire et à relire pour entrer dans l'univers de cet écrivain "né en Inde, incarné en Afghanistan et réincarné en France”.

\section{Mémoires d'outre-mer}

\section{de Michaël Ferrier (Gallimard)}

Partir sur les traces de son grand-père acrobate arrivé en 1922 à Madagascar donne à Michaël Ferrier l'occasion de réaffirmer avec panache ses convictions : il faut être d'une bêtise de bûche pour distinguer les Français de souche, l'histoire de France ne se limite pas à l'Hexagone, l'identité française doit aussi être abordée par ses marges... Des thèmes que l'on trouvait déjà dans Sympathie pour le fantôme (Gallimard, prix de la Porte Dorée 2011). C'est à 17 ans que l'aïeul quitte son île Maurice natale dans les bagages d'un cirque ambulant. Là, il rencontre Pauline, dont la famille vient de Goa la métisse. Pauline est musicienne, elle aime les "musiques migrantes, ces mélodies nées du murmure du monde". Pour évoquer ce grand-père extravagant et cette île exubérante, le style virevolte, ondoie, flamboie. Mais tout n'est pas que fêtes à Madagascar, l'auteur analyse la perversité de la colonisation avec sa République pyramidale "où il est difficile à ceux qui ne sont ni français ni blancs de se faire une place". Puis vient la guerre, avec la politique de Vichy et le "Projet Madagascar", par lequel les nazis, "rêvant d'étoiles jaunes sur l'île Rouge", veulent expédier sur l'île les juifs d'Europe. Plus qu'une saga familiale, le rappel d'une histoire oubliée.

Ces romans mettent l'actualité en perspective ils l'éclairent aussi, en évoquant d'autres drames, d'autres périodes de l'histoire. La littérature, les écrivains et le prix littéraire de la Porte Dorée ont plus que jamais leur place au Musée national de l'histoire de l'immigration. I 